\section{Dispute over rock dating settled out of court}

Rex Dalton, San Diego

An Earth scientist from Columbia University in New York has settled a lawsuit filed against him last year by a geographer in Tempe, Arizona.

The dispute between Wallace Broecker, a professor of Earth science at Columbia's Lamont-Doherty Earth Observatory, and Ronald Dorn of Arizona State University (ASU) began when Broecker co-authored an article in Science questioning Dorn's rock-dating techniques.

Three weeks ago, Broecker and his university made a confidential settlement with Dorn. The amount of the settlement was not disclosed, but sources say it is between $\$ 30,000$ and $\$ 70,000$.

Declining to discuss the case, Broecker issued a brief statement: "[We] have resolved the litigation and have agreed that any scientific disagreements ... should be debated in the scientific arena and not addressed through litigation." Neither Dorn nor his Phoenix-based attorney would comment.

In June 1999, Dorn sued Broecker and his co-authors from the University of Arizona in Tucson, Northern Arizona University (NAU) in Flagstaff and a Swiss institute for defamation, intentionally causing emotional distress and intentional interference with his work.

Dorn's lawsuit against the remaining scientists is continuing in state court in Phoenix. The defendants are expected to seek its dismissal.

The lawsuit was based on an article that claimed that Dorn's samples of rock varnish appeared to contain bits of coal and charcoal, which when combined could distort radio-carbon tests (Science 280, 2132-2139; 1998). Dorn's technique involved scraping varnish off rocks, treating it and then submitting the samples for radio-carbon dating.

A complaint about Dorn's rockdating procedures was also made to the National Science Foundation (NSF), which had funded some of his work. The NSF investigation was closed after an ASU inquiry cleared Dorn in September 1999 of fabricating data in published articles (see Nature 401, 629; 1999).

Dorn continues to work at ASU, where he is part of a team of 20 scientists seeking funding for informationtechnology studies associated with ASU's NSF-funded Long-Term Ecological Research Project.

\title{
Germany rues 'complacency' over BSE testing strategy
}

Alison Abbott and Quirin Schiermeier, Munich The German government has been prompted to order extensive tests on cows following the identification last week of two cases of BSE (bovine spongiform encephalopathy) in German-born cattle. Within the next few weeks it should learn whether these cases represent only the tip of an iceberg.

Many scientists fear that the true extent of the disease may have been hidden. Germany had declared itself 'BSE-free', largely because its farmers have not traditionally fed their cattle on the blood and bone-meal that are thought to have sparked the crisis in Britain.

The precautions taken have therefore not been as rigorous as in other countries. When Britain banned the use of bone-meal as feed in all farm animals, for example, Germany banned its use only in cattle, allowing it to continue in pigs and poultry.

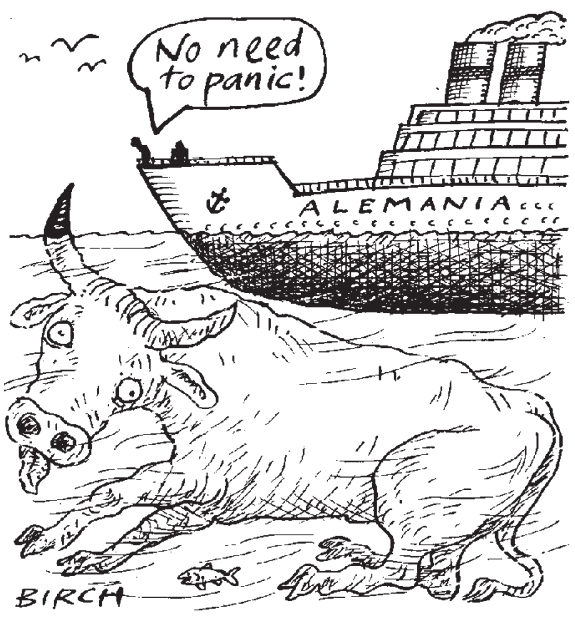

Moreover, Germany has only carried out BSE tests on animals showing symptoms of central nervous system disturbance - there have been around 15,000 such tests in the past ten years.

The federal government has now called for testing of all cattle at high risk of developing BSE, including those dying of unknown causes. Such cases average 66,000 per year. Cattle slaughtered over the age of 30 months might also be added to the list, because older cattle have a higher risk of accumulating the infectious prions thought to cause the disease.

In the wake of last week's discovery, some scientists say that German complacency was misplaced. Hans Kretzschmar, a prion expert at the University of Munich, and a member of an ad hoc group of experts called on occasionally to advise the government, regrets that scientific advice on the matter was not institutionalized in Germany. "There was a feeling that Germany could never be affected by BSE, so a standing advisory committee would not be necessary," he says.

"But when an animal born in Germany in 1996 contracts BSE, even though the use of blood and bone-meal was banned in cattle in 1994, you start to wonder what can be believed," Kretzschmar says. He warns that variant Creutzfeldt-Jakob disease, the human form of BSE, may now arrive in Germany.

"We have been too complacent in assuming that Germany was immune," says Reinhard Kurth, head of the Robert Koch Institute, the government agency that researches into infectious diseases. Kurth regrets what he sees as the general lack of a sound scientific basis in dealing with BSE issues.

\section{Chinese science goes to Earth}

David Cyranoski

Earth sciences will be the focus of a concerted push by the Chinese Academy of Sciences, which last week formally opened its new Institute of Geographic and Natural Resources Research.

Formed by the merger of two older institutes, the new institute is part of a wider academy reorganization announced two years ago (Nature 394, 710; 1998).

About 400 scientists will join the institute from the old Institute of Geography. Of those, about 250 will take part in a new incentive programme, designed to encourage a more competitive approach to research.

Scientists can apply to be part of this programme "if their research interests align with the institute's strategy", according to Li Xiubin, the institute's deputy director. He adds that this will entail a strong emphasis on basic research. Projects inside the incentive programme will be evaluated every two years to determine whether they can continue.

Other employees of the former institutes will be moved to a company providing services to the new institute, which will eventually be spun-off from it.

The academy's old organization was largely modelled on that of the former Soviet Union during the 1950s and was badly in need of reform. Now it plans to streamline its 123 institutes - which house many of China's best scientists - and reduce its staff from 68,000 to 30,000 by 2010 . 